\title{
The bodily-attitudinal theory of emotion
}

\author{
Jonathan Mitchell ${ }^{1}$
}

Accepted: 30 September 2020/Published online: 10 October 2020

(C) The Author(s) 2020

\begin{abstract}
This paper provides an assessment of the bodily-attitudinal theory of emotions, according to which emotions are felt bodily attitudes of action readiness. After providing a reconstruction of the view and clarifying its central commitments two objections are considered (absence of bodily phenomenology and what kind of bodily awareness). An alternative object side interpretation of felt action readiness is then provided, which undermines the motivation for the bodily-attitudinal theory and creates problems for its claims concerning the content of emotional experience. The conclusion is that while the bodily-attitudinal theory marks out a distinctive proposal concerning the question of what emotions are, there remain significant issues which need addressing if it is to be a plausible competitor to existing theories of emotion.
\end{abstract}

Keywords Emotions · Body $\cdot$ Experience $\cdot$ Phenomenology $\cdot$ Awareness

\section{Introduction}

The question of what emotions are is the most fundamental issue in the philosophy of emotion. In answering this question in different ways we get diverging theories of emotion. Julien Deonna and Fabrice Teroni have proposed a new theory, the attitudinal theory, which tells us what emotions are. Broadly, the view is that emotions are evaluative attitudes, such that different emotion types are distinct evaluative attitudes. More specifically, emotions are evaluative attitudes towards intentional contents provided by other mental states-their cognitive bases, such as judgements, imaginations, and perceptions. In contrast to Evaluativist views (e.g.,

Jonathan Mitchell

jonathan.mitchell@manchester.ac.uk

1 University of Manchester, 24 Oaks Road, Kenilworth, WA CV8 1GE, UK 
Judgementalism and Perceptualism), the relevant contents are claimed to be nonevaluative; thick evaluative properties like the disgusting, dangerous, terrifying, humorous, and admirable-which are connected to the individuation and intelligibility of emotions - are not part of the content of emotional experience. Although, the relevant emotion is correct iff the object provided by the cognitive base exemplifies the relevant evaluative property. As such emotional experiences, as felt evaluative attitudes, stand in intentional relations to values without being about values. ${ }^{1}$

This paper critically assesses a substantive development of the attitudinal theory, which I call the bodily-attitudinal theory of emotion, as expressed in the claim that emotions, as evaluative attitudes, are felt bodily attitudes of action readiness. ${ }^{2}$ The critical reception of the attitudinal theory has centred around its claims, documented above, concerning the content of emotional experience and the associated epistemology of value and emotion. ${ }^{3}$ Comparatively less has been said about how the theory is developed in terms of felt bodily attitudes of action readiness-which will be my focus here (as such this paper does not primarily concern the former issues or alternative non-bodily formulations of the view).

Let me briefly say something about the motivation for focusing on the Attitudinal view so thoroughly. First, Attitudinalism has emerged as the main contemporary competitor to Perceptualism and Judgementalism, and so a thorough critical evaluation of it is central to a proper understanding of (a) the direction of travel in emotion theory over the last decade, (b) the standing of the current theories on offer, and (c) potential avenues for further research. Connected to this, Attitudinalism (as noted above) bucks the trend of various stripes of Evaluativism insofar as it does not place values at the level of content. More specifically, the idea that emotions are distinctive felt bodily attitudes of action readiness promises to reframe the way in which emotions are evaluative experiences, and so an assessment of the theory is crucial to the project of understanding the connection between emotions and value (a central theme in contemporary philosophy of emotion). Finally, the bodilyattitudinal theory, as we shall see, promises to incorporate a number of critical points of agreement in the philosophy of emotion concerning the intentionality of emotion, while preserving the Jamesian idea that the body (more specifically bodily phenomenology) is central to a correct understanding of emotions. Given this, it is of paramount importance to provide an assessment of the extent to which this theory manages to successfully reconcile the intentionality of emotion with the (supposed) centrality of bodily feelings in emotional experience.

The discussion proceeds as follows. After offering a reconstruction of the view (Sect. 1), two objections are considered (Sect. 2). These are the 'absence of bodily

\footnotetext{
1 See Deonna and Teroni 2012: Ch. 7; 2014: 25-29; 2015: 293-311; 2017 55-63; 2020: 1-23. Deonna and Teroni commit to the strong supervenience of values: the cognitive base presents non-evaluative properties that jointly constitute the relevant evaluative property.

2 Aside from Deonna and Teroni, approximations of this view are held by Claparède 1928: 124-139; Slaby 2008: 429-444; Colombetti 2011: 293-313; Scarantino 2014: 155-185.

3 See Smith 2014: 102-106; Dokic and Lemaire 2015: 271-292; Müller 2017: 281-308; Rossi and Tappolet 2018: 113-183.
} 
phenomenology', and 'what kind of awareness' objections, which relate to the views' reliance on bodily-phenomenology and the positing of a distinctive kind of non-intentional awareness. Finally, Sect. 3 focuses on felt action readiness and suggests an 'object-side' interpretation, which contrasts with that provided by the bodily-attitudinal theory. This 'object-side' interpretation also serves as a positive proposal for how we can theorize about the phenomenology of action-readiness in emotional experience in a way that is not tied to the bodily-attitudinal theory.

The overall claim of this paper is that while the bodily-attitudinal theory is a distinctive proposal concerning the question of what emotions are, there remain significant issues which need addressing. Defenders of the view should, therefore, meet the challenges set out here if they wish to preserve the theory.

\section{Felt bodily attitudes}

\subsection{Clarifying the attitudes}

To better understand the attitudinal theory, we can make some clarifications concerning psychological attitudes. The attitudes in question are intentional attitudes, such that they are about something or directed toward something. Familiar candidates are propositional attitudes like belief, desire, supposition, wonder, hope, conjecture, and judgement. In these cases, the attitudes take the relevant propositions as objects or are directed toward (or perhaps related to) propositional contents, specified in terms of the objects under aspects, say as having relevant properties (e.g. the belief that the sun is $73 \%$ helium). However, the class of intentional attitudes is not exhausted by propositional attitudes. There are also nonpropositional attitudes, such as perception, visual imagination, and episodic memory.

The attitudinal theory holds that emotions get their intentional content from the psychological states on which they are based-their cognitive bases-and so inherit their (non)propositional content. So, for the sake of simplicity, and bypassing questions concerning the (propositional or not) structure of the relevant basing contents, we can talk of the relevant emotional attitudes as attitudes towards objects (and their properties). We can understand the notion of 'object' in a broad and metaphysically undemanding way, as equivalent to what emotion theorists call the particular objects of emotion (e.g. physical particulars, persons and animals, events, and states of affairs involving such things). ${ }^{4}$

Building on the above, it helps to make explicit a distinction-central to the attitudinal theory-between attitude (or mode) and content. For propositional attitudes like ' $\mathrm{S}$ believes that $\mathrm{P}$ ', we can distinguish between the attitude, in this case believing, and the content, 'P'. This distinction is important because if we can individuate content separately from attitude, then the same content can be entertained by different attitudes. For example, we can say ' $\mathrm{S}$ believes that P',

\footnotetext{
${ }^{4}$ See Lyons 1980 and Teroni 2007: 395-415.
} 
but also ' $\mathrm{S}$ desires that $\mathrm{P}$ ', where the (propositional) content remains the same. If one extends the range of intentional states to include intentional experiences, arguably the distinction still applies. Consider a paradigmatic visual experience, which takes a physical particular as its object. Arguably, its presentational content can be taken up by different non-propositional attitudes, such as visual imagination.

Emotions are often included in lists of intentional attitudes in discussions of intentionality. ${ }^{5}$ This is unsurprising since typical emotions are intentional states in at least the minimal sense that they are directed toward particular objects, and so have intentional content. ${ }^{6}$ For example, in a paradigmatic episode of anger, there is something I am angry about, such as the individual who just insulted me. Likewise, in a paradigmatic episode of happiness, there is something I am happy about, such as having just won the race. Emotion-types like fear, anger, love, regret, grief, and sadness are, therefore, intentional attitudes. Moreover, on the attitudinal theory, emotions admit of the attitude-content distinction. For example, Fred judges that the dam will flood, while Gill fears it will. Furthermore, within the class of emotions, Fred can hate whom Gill loves, or despise what Gill admires. So, emotions putatively involve attitudes towards independently specifiable contents, that is, contents which can be individuated separately from the emotional attitude.

This paper does not question the applicability of the attitude-content distinction to emotions; it is, however, relevant to the discussion that follows. Let me now outline further distinctions between types of intentional attitudes.

First, we can distinguish between occurrent and dispositional attitudes. An example of the latter is Fred's belief that the earth is round. Fred need not be consciously entertaining this belief. Nonetheless, it makes sense to attribute it to him given that he is disposed to do such things as assent to it if questioned, use its content as a premise in an argument, and generally behave in such a way as seems premised on its truth. Contrastingly, when debating a 'flat-earther', Fred explicitly entertains his belief that the earth is round; he brings that content 'before the mind', and explicitly assents to it (either in thought or speech) - as such the belief is occurrent.

Second, consider that there are intentional attitudes with a phenomenology, and so for which there is something-it-is-like to have them (i.e. experiential attitudes). Belief or judgement, and perhaps propositional attitudes more broadly, are controversial examples since arguably there is nothing it is like to, for example, occurrently judge that the earth is round (although those who defend cognitive phenomenology disagree). ${ }^{7}$ However, those intentional attitudes which are determinate types of intentional experience, like perception, imagination, and episodic memory, have distinctive phenomenologies, in virtue of being occurrent determinate types of experience, and as token experiences of the relevant type.

Based on these distinctions, we can provide a clarification of the attitudes posited by the attitudinal theory. The evaluative intentional attitudes, which emotions

\footnotetext{
5 See Searle 1983: 1-4; Dennett 1978: 3.

${ }^{6}$ See Deonna and Teroni 2012: Ch. 1; Lyons 1980: Ch. 7.

7 See Pitt 2004: 1-36.
} 
putatively are, are claimed to be occurrent experiences, with a distinctive phenomenological profile (or at least this is the paradigm case). However, the theory further specifies these evaluative attitudes as felt bodily attitudes of actionreadiness. So, let's turn to this development of the view as a bodily-attitudinal view.

\subsection{The bodily-attitudinal theory}

To understand the development of the attitudinal theory in terms of felt bodily attitudes of action-readiness, it is helpful to consider two related theories of emotion.

First, let's look at somatic feeling theories of the kind formulated initially by William James. Such theories specify occurrent emotions in terms of interoceptive awareness of bodily changes, as conscious awareness of internal physiological changes which happen as a result of excitation. ${ }^{8}$ Anger, for example, as a distinct emotion type, is specified in terms of a range of relevant felt bodily changes, including increased heart rate, muscle tension, increased blood flow, and perspiration. According to such theories, our conscious awareness of those occurrent changes is the emotion; an emotion is the range of (for James, peripheral) physiological changes experienced when undergoing it. We can say more about the causal antecedents of emotions, and the characteristic actions following from them. Nevertheless, these are not components of emotion according to original somatic feeling theories.

The bodily-attitudinal theory accepts the following central claim of the somatic feeling theory

Bodily Phenomenology claim: The phenomenology of emotional experience is (principally) bodily.

However, the bodily-attitudinal theory qualifies this. The relevant bodily phenomenology is not, pace the original somatic feeling theory, that of atomistic (i.e. distinct, specific and singular) bodily changes, for example, one's heart racing, or sweaty palms. Rather, it is holistic. More precisely, the bodily phenomenology in emotional experience is an overall state, which integrates a variety of information from different sources, such as facial feedback, the autonomic nervous system, and changes in skeletal muscles, combining into a synthetic bodily feel—as a putative bodily gestalt. ${ }^{9}$

Given the above, we get the following claim

Holistic Phenomenology claim: The phenomenology of emotional experience is (principally) a holistic bodily phenomenology.

Supporting this, emotion psychologists Anthony Marcel and John Lambie claim that it is implausible that explicit awareness of atomistic bodily changes is part of

\footnotetext{
8 See James 1884: 188-205.

9 See Deonna and Teroni 2012: 79; 2014: 27-29; 2015: 302; 2017: 59-62; 2020 18-22. See also Claparède 1928: 128 and Slaby 2008: 431, 437.
} 
emotions first-order phenomenology-that is before taking a reflective stance or attentive attitude towards one's emotion or aspects of it. If this is true, then the awareness of bodily changes posited by the somatic feeling theory requires secondorder acts of analytic attention. ${ }^{10}$

So, for the bodily-attitudinal theory, the experiential dimension of the evaluative attitudes (which emotions are) is specified in terms of a holistic bodily phenomenology. It bears noting that a qualified somatic feeling theory could accept the Holistic Phenomenology claim if the idea is that in emotional experience the body is given as the whole body-as an overall synthetic bodily feel. It could specify occurrent emotions in terms of an interoceptive-proprioceptive conscious awareness of this putative bodily gestalt. However, the bodily-attitudinal theory rejects a central aspect of somatic feeling theories (even so qualified) and puts the idea of a holistic bodily phenomenology to use differently.

To see how, consider what the bodily-attitudinal theory rejects about somatic feeling theories

Interoceptive Intentionality claim: the fundamental kind of intentionality in emotional experience is interoceptive (i.e. as directed towards the body).

The bodily-attitudinal theory does not, however, reject the claim that emotional experiences are intentional states. Instead, it appeals to a different kind of intentional directedness.

To clarify this, consider Perceptualist theories of emotion (hereafter Perceptualism). Broadly, Perceptualism claims that occurrent emotions either are or involve perceptual (or perception-like) experiences of evaluative properties, as typically instantiated in the subject's environment, or as exemplified by particular objects in that environment. ${ }^{11}$ Fear, for example, involves a perceptual experience of a particular object as fearsome; disgust involves a perceptual experience of a particular object as disgusting. This feature is supposed to be analogous to the way typical sense-perceptual experiences represent empirical properties (e.g., shape, colour, movement) as properties of their intentional objects, and so in good cases either involve or constitute direct access to such properties. Moreover, it is plausible that the intentional content of these experiences, so specified in terms of the relevant represented properties, partly determine what-it-is-like to undergo the relevant experiences. Just as there is something-it-is-like to enjoy a perceptual experience of a red and rectangular table, there is something-it-is-like to enjoy an emotional experience of a particular object as fearsome. This rough outline of Perceptualism suffices for our purposes.

The bodily-attitudinal theory rejects essential claims of Perceptualism; principally (1) that evaluative properties figure at the level of content, and (2) the contingency of any bodily phenomenology. ${ }^{12}$ However, it sides with Perceptualism

\footnotetext{
${ }^{10}$ Lambie and Marcel 2002: 23.

11 See Tappolet 2016: Ch. 1; de Sousa 2002: 255; Johnston 2001: 181-214; Poellner 2016: 1-28. The disjuncts 'either are or involve' and 'perceptual or perception-like' are not trivial-they mark out differences between strong and weak versions of Perceptualism.

12 See Deonna and Teroni 2012: ch. 6 for further points of departure.
} 
over somatic feeling theories on an important point. In contrast to the latter, and the Interoceptive Intentionality claim, Perceptualism characterizes emotional experiences as having a fundamentally exteroceptive kind of intentionality, as directed outward toward particular objects in 'the world', rather than 'inward' towards the body. As such, we get the following claim:

Exteroceptive Intentionality claim: the fundamental kind of intentionality in emotional experience is exteroceptive (i.e. as directed towards 'the world'). ${ }^{13}$

The bodily-attitudinal theory accepts this, but also commits to the following claim:

Phenomenal Intentionality claim: there is a felt 'aboutness' to emotional experience which (partly) accounts for how it feels to have the relevant emotion.

This claim posits a link between the phenomenology and intentionality of emotional experience. In emotional experience, there is not just the experience of the object, but an experience of being so directed toward the object, as felt aboutness, or intentionally directed phenomenal feeling. ${ }^{14}$

Now that we have outlined three central claims - Holistic Phenomenology, Exteroceptive Intentionality, and Phenomenal Intentionality - consider how the bodily-attitudinal theory combines then:

Combined claim: There is a felt aboutness to emotional experience, which (partly) accounts for how it feels to have the relevant emotion, as directed outward toward the world; yet the what-it-is-likeness of this felt (exteroceptive) aboutness is fundamentally characterized by a holistic bodily phenomenology.

In a slogan: emotional experience is intentionally about 'the world' not 'the body', but it is about the world in a bodily way. More precisely-and using the attitudecontent distinction-emotional experience is a bodily-attitude, manifest in terms of a holistic bodily phenomenology, which targets the relevant 'worldly' particular objects, and so has the relevant content. The holistic bodily phenomenology which putatively characterizes emotional experience is the means by which emotional experiences are directed outward towards their objects. ${ }^{15}$ On this basis, the central claim of the bodily-attitudinal theory concerning the intentionality and phenomenology of emotions can be framed as follows:

Bodily Intentionality claim: the felt 'aboutness' of emotional experience, which (partly) captures what-it-is-like to undergo the relevant emotion, is one of the body being directed towards - taking a specific attitude towards - the world (i.e. the body as directed towards the world).

\footnotetext{
13 The Exteroceptive Intentionality claim glosses over a complication concerning the intentionality of reflexive emotions (e.g. self-directed pride, shame). However, reflexive emotions are not directed toward bodily states, and have, as part of their intentional content, some particular object in the world.

14 For a defence of phenomenal intentionality see Horgan and Tienson 2002: 520-533 and Kriegel 2013: 1-26. See Goldie 2000: ch. 3 on 'feelings towards'; see also Kriegel 2014: 424.

15 See Deonna and Teroni 2015: 302
} 
I now further clarify this bodily-intentionality.

\subsection{Clarifying bodily intentionality and action-readiness}

First, it bears re-emphasizing that the bodily intentionality in question is not that of the mind directed towards the body, as is characteristic of somatic feeling theories. ${ }^{16}$ As Deonna and Teroni put it: "emotions are not attitudes we take towards our body, but felt bodily attitudes directed towards the world'. ${ }^{17}$ How are we to better understand the felt bodily intentionality posited by the bodily-attitudinal theory? Moreover, how does this aspect of the view connect to the claim that the relevant bodily attitudes are evaluative? After all, Deonna and Teroni claim it is on the basis of their phenomenology that emotions relate us to evaluative properties. ${ }^{18}$ These two issues are clarified in the appeal to the bodily phenomenology being of a holistic action-ready kind. ${ }^{19}$

Remember, the claim is that the bodily phenomenology of emotional experience is a synthetic gestalt which integrates bodily information from a wide variety of sources. The relevant bodily changes (or at least a significant portion of them) combine at the personal level into a holistic action-ready bodily phenomenology which is said to be global and outward-looking. As such, the relevant bodily attitudes are of a holistic action-ready sort. Further to this, and connecting with the evaluative dimension, these felt bodily attitudes of action-readiness contribute essentially to the world being presented to the subject in various (evaluatively significant) ways because of their holistic action-ready character. ${ }^{20}$

Consider fear directed towards an approaching dog. Fear of the dog is an experience of the dog as dangerous because it consists in feeling the body's readiness to act to diminish the dog's likely impact, such that one's body is ready to 'contribute to the neutralization of what provokes the fear'. ${ }^{21}$ Alternatively, consider disgust towards rotting meat. Disgust towards the rotten meat is an experience of the meat as disgusting because it consists in feeling the body's readiness to act to 'prevent the object from entering into contact with it'. ${ }^{22}$ Finally, consider aesthetic admiration towards a painting. Admiration for the painting is an experience of the painting as beautiful because it consists in feeling one's body open up to sustained and expanding exploration of the painting. One might wonder

\footnotetext{
${ }^{16} \mathrm{NB}$ : this is the model of intentionality adopted by intentionalists about bodily sensations (see Crane 2003: 1-27).

17 Deonna and Teroni 2012: 80 (see also Slaby 2008: 436).

18 Deonna and Teroni 2012: 79.

19 For discussions of action readiness in the psychological literature, see Arnold 1960; Frijda 1986, 2007 (see Sect. 3).

${ }^{20}$ See Deonna and Teroni 2012: 79-80; 2015: 303; 2020 20-22.

21 There is the further claim that the fearing attitude, so specified in terms of its holistic action-ready character, is correct iff the object has the relevant property. Put otherwise, it is correct to 'neutralize' what provokes fear iff it is a threat, and that is why the attitude is said to be both fitting and reasonable if the dog is, in fact, dangerous (cf. Dokic and Lemaire 2015: 280).

22 Deonna and Teroni 2012: 80-81.
} 
whether all emotion types could be individuated in this way. While this is an important issue, let's put it to one side for the moment (issues related to it arise in $2.1)^{23}$

So, bodily phenomenology of the relevant holistic action-ready sort-as an outward-looking form of bodily consciousness-is central to precisifying the supposed felt bodily intentionality of emotional experience, in which the world is presented as significant (i.e. evaluatively relevant). As Deonna and Teroni put it 'the idea that emotions are felt bodily stances we take towards aspects of the environment is amenable to the idea that they are evaluative attitudes'. ${ }^{24}$

In sum, we putatively get bodily feelings into emotional experience in the right way by specifying the relevant exteroceptively directed evaluative attitudes, which emotions putatively are, in terms of holistic felt bodily attitudes of action readiness. As such the holistic bodily gestalt — which captures both emotional phenomenology and its felt aboutness - has significance beyond the body; this holistic bodily gestalt puts us into direct contact with matters of (seeming) significance 'in the world'. ${ }^{25}$ We now have a clarified proposal concerning the nature of the felt bodily intentionality and phenomenology of emotional experience on the bodily-attitudinal theory. The next section considers objections.

\section{Objections to the theory}

\subsection{Absence of bodily phenomenology}

Even granting, for the sake of argument, that felt bodily attitudes of action readiness constitute the exteroceptive (phenomenal) intentionality of some emotional experiences, arguably they cannot do so in all cases. This is because certain 'cool' or 'calm' emotional experiences, such as admiration, reverence, and regret, can arguably occur without any attendant bodily phenomenology. ${ }^{26}$

Consider the following case. Out walking in the Alps, Gill feels moved when confronted with a particularly stunning vista. We might think it plausible that someone can experience such an emotion without any action-ready bodily phenomenology. Consider the following modification. Say Fred has been severely

\footnotetext{
${ }^{23}$ This 'specificity objection' is a central objection to the Jamesian theory (see Deonna and Teroni 2017: 55-59).

24 Deonna and Teroni 2020: 20. The model of intentionality is therefore not analogous to displaced perception, namely seeing that such and such is the case on the basis of a (non-epistemic) seeing of something else. The view is not that I judge that the particular object of my emotion is significant by having an experience of the relevant bodily phenomenology, such that I am indirectly aware of significance in the world by being directly aware of my body, where the presence of the relevant bodily phenomenology is a reliable indicator of such significance. This latter view is close to Prinz 2004. Deonna and Teroni rule this out 2012: 86.

25 Colombetti (2011: 297, 310) goes further, suggesting that the relevant holistic bodily phenomenology puts us in contact with evaluative properties (cf. Dokic and Lemaire 2015: 280).

26 See Lambie 2009: 272-280; Poellner 2016: 13; Stocker 2010: 401-423; Prinz 2004: 57, 72; James 1884: 191, cf. Ibid: 201-202.
} 
physically paralyzed from the neck down, such that he is incapable of experiencing interoceptive-proprioceptive action-ready bodily phenomenology. Nonetheless, Fred is taken to see the stunning vista. It is plausible that Fred could be emotionally moved by the grandeur of the natural scene even though ex hypothesi he cannot experience the relevant phenomenology. Something similar is arguably empirically verified in cases of individuals with severely impaired bodily feedback and awareness, such as those with severe spinal cord injuries who nonetheless enjoy rich emotional lives. ${ }^{27}$

The upshot is that if bodily phenomenology is not essential to some emotional experiences, this undermines the claim that holistic bodily feelings of action readiness constitute the intentionality of emotions since the relevant bodily phenomenology is not present in those cases. Such 'cool' or 'calm' emotions may have associated bodily phenomenologies of the relevant action-ready kind; in the case of being moved by the natural scene, subjects may typically experience a form of bodily relaxation connected to an explorative posture. However, it seems possible to experience awe without such action-ready bodily phenomenology. Further to this, even in those cases where there is action-ready bodily phenomenology, consideration of cases without it brings into question whether it is this aspect of emotional experience which presents the particular object as significant. Furthermore, actionready bodily phenomenology may seem inessential to the emotionality of the relevant experience since it is possible to have the emotion without it. ${ }^{28}$

One way of responding to this objection is to claim that the relevant 'cool' or 'calm' emotions are higher cognitive emotions and that the bodily-attitudinal theory does not apply to these, but to a more limited class (e.g. fear, disgust, happiness, sadness). One could also claim that the relevant non-bodily cases are evaluative judgements, which may have essential links to emotions but are not equivalent to them, and possess different phenomenological profiles. Another route would be to insist on dispositional readings of the relevant class of emotion reports, such that there is no occurrent mental state with a putative non-bodily emotional phenomenology.

However, regardless of the plausibility of such moves, they restrict the scope of the view in an unappealing way. The better response would be to argue that, despite claims to the contrary, there are no 'cool' or 'calm' emotions, where that is taken to

\footnotetext{
27 Cobos et al. 2002: 251-269. This is reminiscent of Cannon's (1927) challenge to Jamesian somatic feeling theories. See Smith (2014: 101-102) who questions whether the bodily-attitudinal view can appeal to the 'as if loop' response (Damasio 2006: 155) where one simulates the relevant bodily state. Smith's worry is, broadly, that as originally proposed by Damasio the relevant 'state of feeling' which is simulated in the absence of a genuine bodily response is (on Damasio's taxonomy of the relevant states) non-conscious (see his 2000: 37), whereas the states which Deonna and Teroni are, at least primarily, interested in are conscious episodes which are 'essentially felt' (Deonna and Teorni 2012: 18). As such, the relevant simulated state would not be manifest at the conscious level. However, more needs saying on this issue, and it should be noted if Deonna and Teorni were to adopt a different taxonomy of the relevant states, arguing that the 'state of feeling' posited by Damasio could be manifest at the conscious level then arguably this response would remain a live option.

28 This also raises individuation problems: type-identification of those (non-bodily) emotions in the terms of the bodily-attitudinal theory would not be a live option (see Lindquist et al. 2012: 121-143).
} 
mean the complete absence of the relevant bodily phenomenology. One way to explain intuitions about their possibility would be to claim that thought experiments like the above are parasitic on cases where the bodily phenomenology is less intense. Given the psychological reality of the latter cases, we are tempted to imagine that there could be cases in which there is a complete absence of bodily phenomenology. Although arguably a closer examination of actual cases shows that there is always bodily phenomenology in play. However, as noted above if there are empirically verified cases in which, due to neurological damage, the subject cannot undergo experiences with the relevant action-ready bodily phenomenology, then it will not be easy for the view to dismiss the objection as resting on a confusion between more or less intense instances of bodily phenomenology.

Nonetheless, the view might push the claim that, on closer inspection, we find that it is mistaken to think there is a complete absence of the relevant bodily phenomenology in such cases. Consider the following re-description of our example. Perhaps the subject who is paralyzed from the neck down is still in some sense motivated to move, or be moved, seeking the adjustment of their bodily orientation to see the Alps better. Further to this, the subject can still move their eyes and facial muscles. Moreover, given we are taking a holistic approach to bodily phenomenology, they may also experience increased heart rate and changes in breathing. So, if we account for the role of the full range of bodily feelings, then despite the subject's inability to move, the above experiential components may suffice for an experience of action-ready bodily phenomenology; indeed, once we take such components into account, it looks more difficult to subtract the body altogether.

In response, we may first draw attention to the fact that any motivation which our subject may have to be moved (say by a third-party) to see the Alps better, say as manifest in seeking the adjustment of their bodily orientation, could be accounted for as follows. Arguably what captures some such motivation to be moved is the presence of a non-bodily desire which is a consequence of their prior emotional experience of admiration. What our subject desires is the obtaining of a state of affairs, namely that they are moved in such a way that they can see the Alps better, but that is best construed as a conative state downstream of the emotional experience itself. As such, it is questionable whether the motivational action-ready phenomenology highlighted in the paragraph above is in fact that of admiration, and not rather that of a desire, which while connected to emotion, seems a contingent consequence rather than a necessary feature.

More importantly, though, the central problem with the above line is that the bodily-phenomenology it highlights arguably falls short of capturing an instance of the specific, type-identifying action-ready bodily phenomenology that is said by the theory to characterize admiration. Remember, admiration is said to be an experience of the relevant object as beautiful or admirable because it consists in feeling one's body open up to sustained and expanding exploration of the relevant object. So, concerning the re-described example, we may accept that there is some action-ready bodily phenomenology present, for example in the changes in facial muscles as linked to attention, or increased interest in the object as reflected in increased heart rate. However, what is arguably lacking is the specific rich and complex action- 
ready bodily phenomenology which purportedly constitutes and type-identifies admiration, such that one's body, as an overall bodily gestalt, is felt to open up to sustained and expanding exploration of the relevant object.

Let me expand on this point. We might question how our paralyzed subject can genuinely feel ready-for sustained and expanding exploration, as a rich and complex bodily gestalt (unifying bodily feelings from a wide range of different sources) given their bodily paralysis. Put otherwise, the bodily phenomenology that seems (on the view under consideration) to individuate admiration surely enjoys a richness and complexity which would presumably suffice to distinguish it from other 'positive' emotions that include attentional focus and explorative motivations (such as amorous feeling or affective forms of curiosity) such that that bodily phenomenology goes beyond merely the ability to move one's eyes and facial muscles, and register (some) bodily changes (e.g. increased breathing tempo). ${ }^{29}$ So, while we might grant that the former experiential components are sufficient for an experience of some action-ready bodily phenomenology (and so perhaps some affective state), they are arguably not sufficient, given the claims of the bodilyattitudinal theory, for an experience of admiration. Connected to this point, we might also think that if the action-ready bodily phenomenology in such cases is sufficiently muted or truncated, then it is questionable whether it is the feature in virtue of which the significance of the object is manifest.

Note, the critic of the bodily-attitudinal theory can accept that if the redescription of the example is correct-there is some action-ready bodily phenomenology-then the subject's emotional experience will be different from that of un-paralyzed subjects. Further to this, we need not rule out that subjects with spinal cord injuries have emotional lives that are in some respects different (and perhaps even attenuated) from those of un-paralyzed subjects. However, the bodilyattitudinal theory claims that the relevant action-ready bodily phenomenology typeidentifies admiration as the emotion it is. And arguably in the absence of that specific bodily-phenomenology the theory could read as implying that it then becomes questionable whether our paralyzed subject experiences admiration, and that implication is in need of further clarification and discussion from those who defend the theory.

Generalizing from the above analysis, we can say the following: The objection we have been considering moves from pointing to putative cases in which there is a complete absence of bodily phenomenology to the absence of the relevant bodily

\footnotetext{
29 A further issue interesting issue is whether if the individual in our example was once not paralyzed this would have any effect (or lessen the force of the objection in the body of the text). Presumably, the idea (in defence of the bodily-attitudinal theory) would be that an (experiential) memory of the relevant emotional experience with the associated bodily phenomenology could be invoked as co-present with the experience, and this could 'make up' for the absence of some of the relevant bodily phenomenology. While more needs to be said on this complex topic, one potential issue with such a response would be that it is dependent on our subject having previously thematized (taken as an object of conscious attention) the bodily phenomenology of a previous instance of admiration such they could remember what-it-feels-like, where that would not simply be a matter of remembering the relevant particular object and its properties. There is also the further issue of detailing the connection between whatever bodily phenomenology is still present in such a case and the remembered phenomenology. I thank a referee at Philosophical Studies for drawing my attention to this option.
} 
phenomenology. In the case re-described, as including some action-ready bodily phenomenology, the bodily-attitudinal theory seems to imply, given its commitments, that it is unclear whether admiration is experienced given what bodily phenomenology is present. The critic, however, can push the line that the default presumption, which would need strong considerations to be defeated, is that admiration is experienced, and we should not hamstring what counts as an experience of admiration by tying it so tightly to bodily-phenomenology.

As a final point, a more concessive response from the bodily-attitudinal theory is as follows. What might be appealed to is a broader category of action-ready attentional phenomena, some of which may less saliently involve the body (e.g. directing one's mental attention to a specific object). As such, it would be actiontendencies per se that constitute the outwardly directed phenomenology of emotion, where the former is realized bodily or mentally. Indeed, Deonna and Teroni explicitly mention this as a way of expanding on the theory. ${ }^{30}$ This disjunctive view is a potentially fruitful development of the theory, although since such a view would not be an exclusively bodily view I don't consider its merits here.

\subsection{What kind of felt bodily awareness}

On the bodily-attitudinal theory, awareness of the body is implicated in the emotional experience insofar as it characterizes what Deonna and Teroni call the attendant attitudinal phenomenology. ${ }^{31}$ This attendant attitudinal phenomenology is supposed to be of a holistic bodily and action-ready character, and explanatory of the way the holistic bodily gestalt puts us into contact with matters of significance in the world. However, what kind of awareness is this?

First, note that certain statements of the view might give the impression that the relevant kind of awareness is intentional. In the examples provided, we are told subjects feel the body's readiness to act in relation to the object, and that subjects enjoy an awareness of one's body adopting a specific stance towards an object. ${ }^{32}$ Psychologist Édouard Claparède, an early proponent of a similar view, talks in comparable terms: "what...consciousness seizes in emotion is...the form of the organism itself that is to say its attitude' ${ }^{33}$ These statements give the impression that there are two instances of intentional awareness; (1) awareness of the relevant particular object and (2) awareness of the body's readiness to act, under the relevant aspect (e.g. as hostilely prepared). Neither, however, capture the bodily-intentionality required by the bodily-attitudinal theory, since the one involving the body is mind to object (where the object is a bodily state), rather than body to object. Alternatively, the formulation 'the subject experiences her body holistically as taking an attitude towards a certain object' suggests the intentionality of emotional experience consists of being directed toward this complex whole. As such,

\footnotetext{
${ }^{30}$ Deonna and Teroni 2015: 303 (fn.13).

31 Ibid: 308.

32 See Deonna and Teroni 2012: 79-80; 2015: 303; 2020: 19.

33 Claparède 1928: 128.
} 
emotional experience would include a higher-order intentionality, as directed towards the overall state.

Deonna and Teroni rule out both readings. On the bodily-attitudinal theory, emotional experiences are non-reflective states with only one form of first-order intentional directedness, namely body to object. We are (paradigmatically) neither intentionally aware of the emotion itself, nor intentionally aware of the body; the relevant action-ready bodily state is definitively not supposed to be an object of experience, and so is not part of its content. As they put it: "when appeal is made to feeling of the body here, the 'of' is not that of intentionality. It is rather that of specification and does not refer to the representation of changes in bodily parts, but to...felt bodily engagement'. ${ }^{34}$ So perhaps the above misreadings can be avoided with careful formulations. For example, we might frame the view as follows: emotional experience is a holistic bodily attitude toward a particular object. The problem, however, with this formulation is that it has dropped the 'felt' qualifier to the relevant attitude. However, once that is included-emotional experience is a felt holistic bodily attitude toward a particular object, or is a felt bodily engagement with a particular object — the 'what kind of felt bodily awareness' objection can be raised.

Before pressing this objection, we should note an important distinction between two claims, which the distinction between experiential and non-experiential attitudes (Sect. 1.1) glosses over. The claim that some attitudes are experiential, and so have a phenomenology, might just be taken to mean that the relevant overall state, 'the attitude', is an intentional experience. One can accept this way of thinking about certain attitudes-namely, as determinate types of intentional experienceswhile rejecting the claim that such experiences have any attendant attitudinal phenomenology.

Contrastingly, the appeal to an attendant attitudinal phenomenology is a stronger claim. On this view to claim that the relevant attitude is experiential, or more perspicuously to claim that it is in some sense experienced, is to say that there is a phenomenologically manifest attitudinal component to the experience which is not equated with (a) the overall state being an experience, or (b) the content component (the object as presented in experience). Deonna and Teroni make the stronger claim for the evaluative attitudes which emotional experiences putatively are.

To further see their motivation for positing attendant attitudinal phenomenology in emotional experience, it is helpful to consider the so-called transparency of experience and the way in which emotional experience is non-transparent according to Deonna and Teroni. According to the 'transparency principle', when we introspectively focus on experience itself, rather than what experience is about or directed towards, we arguably find nothing to attend to but (apparent) objects and their properties. As it is sometimes put, we seem to see right through experience to the objects (apparently) outside, including their properties. Consider introspectively attending to a visual experience of a red and round ball. According to some philosophers, the only properties that seem salient - the only properties that capture how things are experientially for me are properties of the (apparent) external object,

34 See Deonna and Teroni 2020: 20. 
that is redness and roundness as represented properties of the ball, not any 'intrinsic' properties of the experience. ${ }^{35}$ Now, according to Deonna and Teroni, this transparency principle is not true of emotional experience: 'as opposed to what happens in perception, the exercise of attending to one's emotional experience as opposed to what it is about does not culminate in the contemplation of the very same properties in both instances. This is clear when we appreciate how switching one's attention from what an emotional experience is about to the experience itself dissolves its intentional structure'. ${ }^{36}$ The fact that emotional experience is nontransparent in this way is suggestive of the claim that 'emotional phenomenology is not exclusively that of something making itself manifest', ${ }^{37}$ and therefore supports the positing of attendant attitudinal phenomenology as a phenomenologically manifest attitudinal component to the experience.

Given the above, we can rule out the following idea. While the relevant bodily feelings, as felt attitudes of action readiness, can be understood as vehicles of exteroceptive content, at the experiential level they are not phenomenologically manifest in any sense, but rather are reflected in the kinds of properties the objects of emotional experience show up as having (e.g. action-ready properties, see Sect. 3). Put otherwise, such bodily feelings would be non-phenomenal constituents, perhaps playing a pre-structuring role. ${ }^{38}$ Such a view would not be committed to any attendant bodily-attitudinal phenomenology.

So, what is needed is a clarification of the kind of bodily awareness implicated by the bodily-attitudinal theory in its talk of felt bodily attitudes, where this goes beyond just saying that the relevant emotions, as kinds of attitudes, are experiences, and further substantiates the supposed attendant attitudinal phenomenology. Moreover, we need to do so without slipping back into intentional characterizations. Meeting this challenge proves difficult.

First, note that the relevant bodily awareness might be modelled after background phenomenological awareness of the body. For example, consider the kind of awareness one has of the pressure of objects on one's body, say the pressure of a chair arm digging into one's side when writing at a desk. When one first sits down and shuffles around to get comfortable, one may have an explicit phenomenal awareness of the bodily sensations of pressure. Though when one 'settles in' such sensations typically fade into the phenomenological background-they are no longer explicitly noticed or attended to.

However, this kind of background phenomenological awareness of the body is not obviously that which the bodily-attitudinal theory requires, as a putative awareness of the attendant attitudinal phenomenology. To see this, note that the posited holistic bodily phenomenology seems like the kind of thing that needs to be at least to some extent more explicitly phenomenologically manifest, that is in the

\footnotetext{
35 Ibid: 308. On the transparency of perceptual experience see Harman 1990: 38; Tye 2002: 139; Martin 2002: 380-381.

36 Deonna and Teroni 2015: 308.

37 Ibid: 308 .

38 This might be closer to what Slaby (2008: 436-440) has in mind.
} 
foreground rather than the background when compared with the awareness of those tactile sensations. Consider the action-ready bodily awareness I putatively have in fear, as my bodies readiness to contribute to the neutralization of what provokes fear; is it natural to describe this as merely peripheral or marginal? At the least, it is not clearly analogous to that 'peripheral' or 'marginal' background phenomenological awareness which subjects have of their bodies when settled into an activity which consumes their attention, that is where bodily sensations fade into the background. Connected to this, it is unclear how a bodily phenomenology which was part of a background, marginal 'phenomenal buzz' in the manner of those background tactile sensations described above could seem to the subject be that which presents significant properties of external objects.

Somewhat bracketing the above worry though, a defender of this approach might say the following in response. In cases in which there is no need to inhibit the emotional response, that is where it is possible to let the action-tendencies 'follow their course', then the attendant attitudinal phenomenology could be thought of as being in the background on the model suggested. Contrastingly, in cases in which we cannot let the emotion follow its course (e.g. I have to restrain myself from physically attacking the individual who makes an offensive comment), or when the emotion is sufficiently 'overpowering' (e.g. being 'struck down' by some terrible news and collapsing), the bodily phenomenology would be in the forefront.

This is an important distinction between different types of cases, although it does lead to a disjunctive account of the kind of awareness subjects have of the relevant attendant attitudinal phenomenology. Further to this, the critic might respond that we need to keep in check a distinction between action-ready phenomenology and the phenomenology of carrying out of the relevant actions themselves. It is plausible that the bodily phenomenology of carrying out the associated actions when 'going along with the flow' as contrasted with 'restrained inhibiting', is very different. Yet, arguably this is a difference in what-it-feels-like to carry out an action which naturally follows from one's emotion-one's action being what one was ready forfrom what-it-feels-like to restrain oneself from the action one's emotion prepared one for. Sexual attraction provides an illustration. Consider the phenomenological difference between moving towards the object of one's sexual attraction and restraining oneself from doing so. This is a distinction between what-it-feels-like to carry out certain actions or not, in the context of one's emotion preparing one for them, rather than a distinction in the kind of background vs foreground awareness we might have of any action-ready phenomenology. Put otherwise, we have hit on a distinction in the phenomenology of action out of emotion, but this marks out a phenomenological contrast downstream from the (putative) action-ready phenomenology of emotional experience. As such, it is not clear we have been provided with a distinction which allows us to answer the 'what kind of felt bodily awareness' objection.

As a final comment on background awareness, let me also note that, regardless of issues about the phenomenology or distinctions between types of cases (which are of course difficult to adjudicate), it is contentious whether background awareness is non-intentional. Consider the case of absorbed writing. While focusing on the laptop screen and keyboard, as the focal point or 'theme' of one's visual experience, the 
table, surrounding books, and scattered papers, all form part of the background, as 'filling out' the visual scene (as the ground in the figure-ground relation). They are, ex hypothesi, not the explicit focus of attention, but they plausibly characterize the phenomenal-intentional background; they are part of what is presented in visual experience, as part of how one is visually appeared to. As such, they contribute to the overall intentional content of the experience (i.e. the visual scene as it appears to me). Given this, it is therefore plausible that we can (and often do) have background intentional awareness, and that, therefore, intentional awareness is not plausibly coextensive with focal phenomenal awareness. But, returning to the bodily-attitudinal theory, any putative 'background' phenomenology of felt bodily engagement, in terms of attendant bodily-attitudinal phenomenology, isn't supposed to have this character. The background awareness required by the view (if it makes this appeal) can't be analogous to our peripheral, background awareness of objects on the margins of our visual field. This awareness is, after all, a species of intentional awareness, and remember according to Deonna and Teroni the relevant action-ready bodily state is not supposed to be an object of experience (even a peripheral or marginal one), and so is not part of its content.

Before moving on, let me highlight a point concerning the preceding discussion. I do not take myself to have definitively ruled out that the bodily-attitudinal view, in its positing of attendant attitudinal phenomenology and a distinctive kind of bodily awareness putatively enjoyed in emotional experience, can appeal to some form of background awareness. Rather I have merely suggested that there are some problems with doing so given familiar models for thinking about such background awareness and that therefore more clarification is required if this is the route that is taken by the view.

Alternatively, one might suggest that the required kind of awareness is so-called 'pre-reflective' bodily awareness, as something that is neither background phenomenal buzz, nor something of which we have 'object' awareness. To substantiate this latter claim, the bodily-attitudinal theory could appeal to the phenomenological notion of the 'lived body'. Giovanna Colombetti clarifies this with the following example:

As I am typing these words, my awareness is mainly focused on the characters that appear on the screen, and on their meaning. Yet at the same time we can say that I am pre-reflectively aware of my fingers as that part of my body through which the typing occurs, and in general of my body as that through which various experiences are made possible. Every perceptual experience is thus in part also an experience of my body. (Colombetti 2011: 531) ${ }^{39}$

We can bracket whether this is credible as a claim about the kinds of awareness implicated in paradigmatic sense-perceptual experience.

The central problem with this proposal as applied to the bodily-attitudinal theory is that it arguably falls prey to some of the same objections considered above concerning the idea of background phenomenal awareness. Remember, the so-

39 See also Zahavi 2005: 63. 
called attendant attitudinal phenomenology is supposed to be of an action-ready holistic bodily kind which possesses a kind of felt aboutness. So, we might think that it is not merely that such phenomenology is a part of the experience which we are not 'mainly' attending to or some manifest condition of its possibility. Instead, it is supposed to characterize the central, indeed definitive, what-it-is-likeness of emotional experience.

To highlight the disanalogy consider the example provided by Colombetti. When, in visual experience, attention is consumed by the relevant object, as in absorbed typing, it is plausible that I don't notice any tactile phenomenology. Perhaps with a switch of attention or breakdown in absorption I can become aware of my fingers as that part of my body through which the typing occurs (e.g. if the words stop appearing on the screen, I may focus attention on my pressing of the keys). However, it is odd to think that any such tactile phenomenology, before some attention switch, exhibits 'felt aboutness', as involving 'awareness of one's fingers adopting a specific stance towards an object', and so as analogous to what Deonna and Teroni say in the emotion case. So even if the notion of the pre-reflective 'lived body' makes sense, ${ }^{40}$ it is not clear whether it is of much help in answering the question of what kind of awareness talk of attendant attitudinal bodily-phenomenology implicates. As such, the bodily-attitudinal theory needs to explain in more detail how it would draw on such notions to answer this problem-which it has not yet.

As a final point on this issue, a defender of the bodily-attitudinal theory might argue that the putative analogy with touch and tactile phenomenology is (for the reasons given) inapt. Alternatively, we can focus on awareness of bodily action towards the environment. In such cases, so the response goes, we have examples of non-emotional felt bodily stances that it makes sense to describe in terms of their targets, for example, the consciousness of one's body when one attempts to jump over an obstacle. However, it is unclear whether this kind of bodily phenomenology is well-suited to enlist in making a case for the bodily-attitudinal theory. One problem is that of distinguishing specifically emotional phenomenology from other cases of bodily-action toward the environment. Consider the following case: The way one's body feels in attempting to jump over a fence, to get to something I am interested in on the other side, may be phenomenologically indistinguishable from, for example, the kind of 'approach and exploration' phenomenology putatively characteristic of certain forms of admiration or emotional curiosity. Further to this what is it about the action-ready bodily phenomenology in the emotion case that makes it apt to present that which is significant for the subject in a way categorically different from the action-ready bodily phenomenology involved in the nonemotional felt bodily stance of attempting to jump over a fence? More needs saying on the connection to bodily action (I return to questions concerning the nature of action-ready phenomenology in Sect. 3). ${ }^{41}$

Based on the above discussion, until we have a more detailed characterization of the kind of bodily awareness implicated by the bodily-attitudinal theory-as cashing

\footnotetext{
${ }^{40}$ In separate work I detail considerations in favour of the view that 'pre-reflective' non-intentional awareness, in general, cannot be made sense of.
} 
out the supposed attendant attitudinal phenomenology-then arguably this aspect of the view is problematic. One position in the philosophy of mind which might be sceptical that the view can make good on precisifying the relevant bodily awareness would be 'Pure Intentionalism'. According to that view, the phenomenal character of an experience is exhausted by its intentional content. ${ }^{42}$ When it comes to mental states and awareness there are only two types: there is phenomenal awareness of objects and their properties (even if only peripherally or marginally), and factawareness, as awareness that 'such and such is the case'. ${ }^{43}$

Importantly, in the course of defending their view, Deonna and Teroni explicitly reject 'Pure Intentionalism' as true of emotions. ${ }^{44}$ Their appeal to an attendant attitudinal phenomenology ties the view to 'Impure Intentionalism' ${ }^{45}$ According to that view, the relevant attitude or intentional mode of the experience is a phenomenologically manifest component which, along with the relevant content, determines what-it-is-like to have the relevant experience (and contributes to individuating it). However, such a view, and the framework it proposes, is controversial. Connecting to the above, one of the central problems, which the bodily-attitudinal theory inherits, is giving a detailed characterization of the relevant kind of awareness we have of the putative attendant attitudinal phenomenology.

However, it bears noting that 'Impure Intentionalism', in general, has a view of intentionality where the relevant structure is still that of a (phenomenologically manifest) mental-attitude to object, not that of a bodily-attitude to object. As such, while the bodily-attitudinal theory falls in with 'Impure Intentionalism' concerning the claim that attitudes make a phenomenological difference-as phenomenologically manifest qua attitudes_-such a 'companions in guilt' response doesn't further clarify the specific bodily awareness implicated by the view. As such, the 'what kind of bodily awareness' objection is significant, and the bodily-attitudinal theory should address it directly.

We can now surmise. This section has raised two objections to the bodilyattitudinal theory. Defenders of the view need to say more about these issues and recognize that the kind of felt bodily intentionality their view posits requires further clarification. However, let me be clear on the import of the discussion. It should be noted that the 'absence of bodily phenomenology' objection was grounded in one detailed example, namely admiration, which it is difficult to account for on most theories of emotion (although perhaps the reader might consider whether similar considerations extend to regret and reverence). More generally, the kind of demarcation problems we have encountered throughout the discussion of both objections - the ability of the theory to distinguish between emotions and non-

\footnotetext{
${ }^{41}$ Note, this is a familiar demarcation problem: on what basis do we distinguish some class of experiences (in this case emotions) from ones that seem non-superficially similar to them. I don't mean to suggest that only the bodily-attitudinal theory has to solve such problems (any theory of emotion has to).

42 See Tye 1995; 2002: 137-151; Harman 1990 31-52; Byrne 2001: 199-240.

43 See Dretske 1999: 39-65 and Shoemaker 1996: 5, 205.

44 Deonna and Teroni 2015: 308-309.

45 See Crane 2003: 1-27; 2009a: 474-491; Horgan and Tienson 2002; 520-533 For a precursor to this view see Searle 1983: 4-6, 12.
} 
emotional mental states, and different types of emotion-is a familiar problem for all theories, so I don't mean to imply that only the bodily-attitudinal view has to find answers to these problems, or indeed that it is only the solutions offered by that theory which are contestable. Finally, it is worth noting that much of discussion of this section has turned on probing and reflecting on specific aspects of the phenomenology of emotional experience qua what is 'implicit' vs 'explicit', in the 'background' rather than the 'foreground' etc. And while the criticisms raised point to areas in which the bodily-attitudinal view needs to do more to clarify and defend its position, these are contentious issues concerning which it would be unwise to level overly-strong verdicts. The next section turns more explicitly to felt actionreadiness to discuss how one might challenge what the bodily-attitudinal theory has to say on this issue.

\section{Felt action-readiness}

\subsection{Object-based action-readiness}

Let me start this section by clarifying the phenomenology of action-readiness, as manifest in emotional experience, by reference to the following passage from Nico Frijda:

Action readiness transforms a neutral world into one with places of danger and openings towards safety, in fear, with targets for kissing and their being accessible for it, in enamoration, with roads stretching out endlessly before one, in fatigue, misery, and despair, with insistent calls for entry or participation or consumption, in enjoyment (Frijda 2007: 205).

Frijda is highlighting a ubiquitous feature of emotional experience, namely felt action-readiness. Deonna and Teroni contend that the bodily-attitudinal theory is especially well-placed to capture it. According to that view, felt action readiness is a matter of holistic action-ready bodily attitudes being directed towards the world, such that our having the relevant action-ready attitudes contributes essentially to the world being presented as significant in various ways. ${ }^{46}$ As they put it: 'in emotion, we feel a bodily attitude towards a given object, which amounts to saying that we feel the way our body is geared towards the object we are facing. The body is felt in the form of a gestalt of bodily sensations, which consists in being ready to respond in a given way to the object'. ${ }^{47}$ If the bodily-attitudinal theory is the best way of capturing the phenomenon of action-readiness, then that is a significant point in favour of the view. It would also offer a way of diffusing previous worries concerning the supposed attendant attitudinal phenomenology; the attendant attitudinal phenomenology is the so-directed felt action-readiness, and that is something with which we are phenomenologically familiar.

\footnotetext{
${ }^{46}$ Deonna and Teroni 2012: 80.

${ }^{47}$ Ibid: 87. See also Claparède 1928: 124-139.
} 
However, the bodily-attitudinal interpretation of action-readiness is not the only way to go. A plausible, and arguably preferable, alternative is presented below by developing further comments from Frijda. The respects in which this alternative is preferable is that it better reflects the relevant phenomenology, as discussed in this section, and can deal more neatly with theoretical issues concerning differences in content-the topic of the final section.

Action-readiness is paradigmatically felt; in typical cases of emotional experience there is a phenomenology of action-readiness. However, nothing forces one into cashing this out in terms of bodily-attitudinal phenomenology. An alternative is framing felt action-readiness in terms of the object seeming a certain way. Note, this does not undermine the action-readiness being 'felt' since objects seeming a certain way is agreed to be part of what determines the phenomenal character of intentional experience. Frijda agrees: phenomenology does not fall out of the picture because 'in first-order emotional experience, the experienced meanings are felt as properties of the objects or events perceived...if attention is fully focused on the world, emotion experience is out there. The meanings are out there, phenomenally'. ${ }^{48}$ Further to this, he claims 'the felt qualities include those of being targets for action, their perceived instrumentality for ongoing or planned actions, their nearness for grasping, 49

This points in the direction of an object-side interpretation of action readiness. Frijda goes on to elucidate action readiness in a way which supports this interpretation:

Action readiness is reflected in the objects' and places demand characters of 'to be removed', 'to be distanced from', or 'to be united with'. The demand characters differ subtly from the affordances and hodological properties. The latter reflect appraisal of what one could or could not do; the former reflect one's being set to do or actually doing, with its control precedence. During emotion, the felt quality, 'desirable' changes into that of 'desired!' of 'an object-to-bepossessed-not-in-possession' into 'the object-to-be-possessed!'. With joy, experience shifts from 'the world as open and available' to 'the world within reach', 'at one's fingertips', 'to-be-participating in'. (Frijda 2007: 205)

So, action readiness in emotional experience has several features: (1) it concerns the particular objects of those experiences; (2) those particular objects possess demand characters; (3) the demand character of particular objects is a way they appear (i.e., part of their aspectual shape). ${ }^{50}$

However, importantly demand character is not to be understood in terms of those objects having everyday affordance or instrumental value properties, as representing generic, and modally open action-possibilities (i.e. 'could or could not'). Demand character is not equivalent to the way objects are presented in what Jean-Paul Sartre

\footnotetext{
48 Frijda 2007: 203-204.

49 Ibid: 203-204.

50 See Deonna (2006: 29-46) for a similar view within the framework of the perceptual theory of emotion, such that we perceive calls for action.
} 
and the Gestalt psychologists call 'hodological space'. We can understand the latter as an external space or environment—what Max Scheler calls a 'milieu'—where the subject has an experiential encounter with everyday objects as instruments or obstacles, which present mere possibilities for action. ${ }^{51}$

So, what is demand character? We can precisify it as the way the particular object, as presented in emotional experience, makes specific calls for action, as imperatives to action. Frijda speaks of the 'urgency of the action calls that targets emanate, the violence of their call as incentives, their appearing irresistible, overpowering, unbidden, not to be lost track of ${ }^{52}$ In this sense, the relevant 'demands' are experienced as demands made by the object of the experience, and so as primitively compelling - as demanding that something should or must be done with respect to itself. Marcel and Lambie label something similar 'gerundival properties', whereby the subject experiences the particular object as impelling that a specific action should or must be performed concerning itself. ${ }^{53}$

Based on the above, we might say the following concerning an object-based interpretation of action-readiness. The phenomenology of felt action-readiness does not include any attendant bodily-attitudinal phenomenology. Instead, the phenomenology of felt action readiness amounts to experiencing particular objects as having the relevant demand characters, as 'calling for...', 'demanding...', 'obstructing...', 'requiring...'. As such, the phenomenology of action readiness admits of an interpretation which builds the relevant action-readiness into the content. It is the objects having the relevant demand character that captures how things are experientially for one in emotional experience qua action-readiness.

Further to the above, in cases where there is a bodily phenomenology of action readiness, it is experienced as an effect of the objects having the relevant demand character. Consider the following example. Fred, stood at one of the lookout points on the Grand Canyon, is surveying a grand vista, and experiences awe. In line with the idea of action-ready demand character, the vista is experientially given as authoritatively calling for exploration. In such a case, Fred may experience an accompanying bodily phenomenology of a non-atomistic sort, say his body 'opening up' or being in an 'explorative posture'. However, any such action-ready

\footnotetext{
51 See Sartre 2004a [1936]; 2004b [1939]: 39, 59; Lewin 1938; Scheler 1973: 154-162; Lambie and Marcel 2002: 238. See Nanay 2011: 305-22 for a contemporary development of these ideas. One might have a sparser view of the contents of perception which would deny that modal properties and imperatives (see the discussion of demand character below) are the sorts of properties that can be (simply) perceived (cf. Siegel 2010). Further to this, we need not take a stand here on questions concerning the ontological status of affordances or instrumental value properties (i.e. whether they are metaphysically objective properties of objects or in some sense subject-dependent) - the analysis is couched at the phenomenological level.

52 Frijda 2007: 205. 'Demand character' so understood-as emotion-specific instrumental value properties-would explain why emotions give us reasons for action; their content includes action demands (e.g. an object presented as making a call for care gives us a motivating reason for caring actions).

53 See Lambie and Marcel 2002: 329. Although they claim (contrary to Frijda) that such properties are not presented in first-order emotional experience.
} 
bodily phenomenology is experienced as, and is arguably intelligible as (makes sense as), an effect of the vista having the relevant demand character.

Importantly, a defender of this object-side interpretation of action-readiness may agree that to account for the experience of any given emotion appeal must be made to a reactive or responsive dimension, as constitutive of the emotion (rather than merely an effect). To undergo an emotion is in some critical sense to be moved by something, in one way or another. They may also concede that merely representing the relevant demand character of the particular object is not per se to be moved in any emotionally relevant (affective) way. Nonetheless, the precise sense of 'being moved', as referring to the relevant affective response or attitudes, is not equivalent to putative felt action readiness 'on the subject-side'. For example, the responsive dimension of standing in front of the vista and experiencing awe, such that one experiences the vista as authoritatively calling for exploration, might be given through affective attitudes that are not necessarily bodily, such as approval, or favour. ${ }^{54}$ In any case, the object-side interpretation of action-readiness is not a fullyfledged theory of what emotions are, but a potential plank in some such theory, and one that seems to run against the grain of the bodily-attitudinal theory. ${ }^{55}$

Building on this discussion is the following suggestion by Frijda concerning the bodily aspect of action readiness:

When attentional focus moves from the world to oneself, experience changes accordingly. The objects now are aspects of my body, my states or my person...in self-focus, action readiness becomes articulate as felt urge-urge with a particular aim, such as for self-protection, or to broaden and build the scope of one's interactions. Felt anger turns from seeing a bastardly offender into felt urge to strike him, to harm him and remove him from his field of action. (Frijda 2007: 205).

This implies that we can better understand the bodily action readiness Deonna and Teroni highlight as a dimension of second-order attention to emotional experience, rather than part of its first-order phenomenology. Put otherwise, it is only in a switch of attention 'from the world to oneself' that we get the felt bodily attitudes of action readiness that the bodily-attitudinal theory claims constitute emotions. ${ }^{56}$

In sum, the question we have been trying to answer is as follows: is the felt action-readiness of emotional experience more faithfully described in terms of the object making a call on the subject to act (as a demand to act in a given way), or as the subject taking a bodily stance or attitude towards the object (as being prepared to

\footnotetext{
54 See Poellner 2016: 1-28 and Mitchell (forthcoming) for one way of developing this kind of view.

55 Note, in the logical space of theories of aspects of emotion, they are nonetheless still relatively close to one another.

56 It should also be noted that in certain passages Frijda (2005: 482) suggests more generally that the intentionality of the emotion - that is its outward-directedness towards the world-breaks down when one switches from 'the world' to the experience'. This observation could be used (as Deonna and Teroni do; see 2015: 308) to make the point that emotional phenomenology is not simply that of something (some object) making itself manifest. I provide a detailed discussion of the relative transparency and opacity of emotional experience in separate work (see Mitchell 2020).
} 
act in a given way). This section has presented reasons to take the former view seriously, as a plausible, and phenomenologically preferable, alternative to the latter. In light of this, the bodily-attitudinal theory needs to do more to defend its interpretation of felt action-readiness

\subsection{Transformation and difference in content}

This section considers a final concern connected to action readiness, which is tied into theoretical issues concerning attitudes and contents, and shows how it creates problems for the bodily-attitudinal theory.

In the passage quoted from Frijda at the beginning of 3.1, he talks of the way action readiness transforms a 'neutral world'. I now examine this modification claim. First, talk of a 'neutral world' in this context pertains to our experience of the world (or objects within it) being presented in a non-emotional way, or by way of non-emotional mental states. In this context, it still makes sense to think of the relevant particular objects as having hodological properties, as everyday instrumental value properties. Now consider the purported 'transformation': Frijda claims in world-directed joy our experience 'shifts' such that previously the particular object (in this case putatively 'the world', but it could be a more common-garden variety particular object), as given in hodological space, was experienced as merely open and available. More precisely, the content of the non-emotional experience can be (partly) specified in terms of the relevant hodological properties of being 'open' or 'available'. When we move to world-directed joy, there is a 'shift'. The world now becomes 'within reach' such that it calls-to-be-participated in. As such, the content of the emotional experience includes such properties or aspects approximating this demand character (e.g. demanding engagement). ${ }^{57}$

Now, if this account of the relevant differences in content concerning a putative 'transformation of a neutral world' in joy-by way of felt action-readiness-is plausible then this creates a problem for the bodily-attitudinal theory. A central aspect of the theory is the claim that emotional experiences get their intentional content from their cognitive bases. Remember, emotions are claimed to be evaluative attitudes towards contents provided by other psychological states-they inherit the content they have from their cognitive bases. Moreover, this is supposed to be a benefit of the view since it preserves the idea - reflected in ordinary language about intentional experience and emotion-that (1) different emotion-types can be (note, not necessarily are) different attitudes towards the same content and (2) different intentional states can have the same content as emotion. Call this the sameness of content claim. ${ }^{58}$ Note, one can accept that, in many cases, content is an important variable to explain why a subject ends up with one emotion rather than another (or no emotion). The relevant claim, therefore, is understood as saying that

\footnotetext{
57 Given this explication, Frijda's 'transformation of the world' is not principally evaluative, in the sense of relating to the presentation in emotional experience of the relevant thick evaluative properties (cf. Goldie 2000: 59-60).
} 
such a difference in content is not necessary to explain why subjects end up with one emotion rather than another (or no emotion), such that there are cases where the content is the same, and the attitudes differ. Nonetheless, because the view accepts this sameness of content claim, it cannot allow the object-side interpretation of felt action readiness as given in terms of demand character. Doing so allows those kinds of 'transformation of the world' accounts to be given, where this arguably points to a difference in content. This conflict is now explained in detail.

The bodily-attitudinal theory has to frame felt action readiness exclusively on the 'subject side' - in terms of supposed attendant bodily-attitudinal phenomenologybecause if felt action readiness, as demand character, was allowed as a specific way the particular objects of emotional experience are presented, and so as an aspect of the content of emotional experience, then it is implausible that the sameness of content claim is ever true. As noted above in the discussion of the 'transformation of a neutral world', the content of an emotional experience, as including demand character, is non-trivially different from any non-emotional state (even if there is overlapping content). Moreover, the demand character of particular emotional experiences_-say fear compared to joy, or melancholy compared to regret-may be non-trivially different along the lines of demand character.

Concerning the latter cases, consider the following as a prima facie plausible example in which the content is the same, but the emotional attitudes differ. Sally and Gill stand in conversation with Bill at a party. Sally is experiencing disgust at Bill, whereas Gill is experiencing admiration for him. Isn't this a case of same content different attitude? Not if we think of the different emotions demand characters. Since on that picture, the shared object (Bill), will be experienced as having different demand characters for the different emotions. Roughly, for Sally, Bill demands withdrawal-from or escape-from, whereas, for Gill, Bill demands approach-to or engagement-with. If this is the case, then the different demand characters will be reflected in a difference in content across the different emotions.

Against this, is it more plausible to insist that both emotions have the same content, but just focus on their object and its properties (Bill) in a different way, where this is cashed out exclusively in terms of different action-ready bodily attitudes with different attendant attitudinal phenomenologies (i.e. a different bodily way)? It is at least as plausible to claim that even in this case, the different emotions present the same object as having different demand characters. Note it will not suffice to reply that the content is the same simply because the cognitive base is the same (that both are based on the same perception) since that begs the question against the alternative we are considering - namely, putative differences in content along the lines of different demand character.

One alternative response in such cases might be as follows: the phenomenology of any given emotion blends in such a way that makes for a unified whole, on the basis of which it is simply not possible to distinguish the phenomenology of attitude and that of content. Yet, such a response is arguably too concessive since it arguably necessitates giving up on talk of attendant attitudinal phenomenology (see 2.3). We

\footnotetext{
58 See Deonna and Teroni 2014: 26-27; 2012: 76-78.
} 
might question what motivation we have for positing an attendant attitudinal phenomenology if in actual cases of emotional experience, we simply cannot distinguish the contribution of attitude vs content with respect to the phenomenology of the experience.

In sum, given the sameness of content claim, the bodily-attitudinal theory cannot allow for content becoming a necessary variable between different emotions, and emotions and non-emotional states which target the same particular object. Yet the necessity of a difference in content along the lines of demand character-drawing on an object-side interpretation of action readiness-is a plausible account of part of what happens in cases of (a) moving from non-emotional to emotional experience with a shared object, and (b) the difference between different emotions directed towards the same particular object. However, if that is the case, then the sameness of content claim looks questionable even if those cases which seem prima facie well suited to support it.

Deonna and Teroni do respond to the objection that the attitude-content distinction does not apply to emotions. ${ }^{59}$ However, nothing in the above account of action-readiness, of demand character on the object-side, necessitates rejecting that distinction. That two experiential states which target the same particular object can differ in intentional content (in some non-trivial respect) does not mean that when considering a token experience, say a particular emotion, we cannot fruitfully distinguish those features of the experience best characterized as contentful vs those best characterized as attitudinal.

What the above discussion points to is the related, but different issue, of whether it is plausible to insist that different emotions, and emotions and non-emotional states, directed toward the same particular object, could share the same content qua demand character. This way of framing the issue has the benefit that it need not reject the attitude-content distinction for token intentional experiences and does not claim that the respect in which content is a necessary variable across emotion-types and relevant non-emotional states (as directed towards the same particular object) concerns the representation of thick evaluative properties -- which the bodilyattitudinal theory rejects. It instead proceeds from a feature of emotional experience, action-readiness, that is agreed to be central to emotional phenomenology, and offers an alternative interpretation of it which is incompatible, or at least in tension with, a claim of the bodily-attitudinal theory.

Of course, the bodily-attitudinal theory may reject the object-side interpretation of felt action readiness, and related ideas of 'transformation' and different demand character as pointing to a necessary difference in content. However, in doing so, the view needs to explain what is problematic about this interpretation; one cannot do this by claiming that we also need to build in action readiness on the subject-side. Given the above, the bodily-attitudinal theory cannot, by its strictures, tolerate any necessary variability on the object-side since this will undermine the sameness of content claim. Further to this, what will also not do is insisting that the object-side interpretation of action readiness (and what follows from it) must be wrong given

59 Deonna and Teroni 2015: 304-307. 
the strictures of the view concerning the sameness of content claim. That would beg the question against the alternative, which intuitively points to explanatorily significant differences in the relevant contents. What is required is a substantive response to this alternative interpretation of felt action-readiness or a qualification of the relevant claims concerning the content of emotional experience. Failing that, the strategy of building all of the distinctiveness of emotional experience into the (bodily)attitudinal side looks questionable.

\section{Conclusion}

This paper has critically assessed the bodily-attitudinal theory of emotion, according to which emotions are felt bodily attitudes of action-readiness. After reconstructing the view, two detailed objections were considered. Finally, an alternative interpretation of felt action-readiness was provided. This also served as a positive proposal concerning how to theorize the phenomenology of action-readiness in emotional experience, which arguably better respects the relevant phenomenology and can deal more neatly with theoretical issues concerning differences in content. So, while the bodily-attitudinal theory of emotion is a distinctive and philosophically substantial proposal concerning the question of what emotions are, which should be taken seriously, there remain problems and issues which need addressing. Defenders of the view should meet the challenges set out here if they wish to preserve the theory.

Open Access This article is licensed under a Creative Commons Attribution 4.0 International License, which permits use, sharing, adaptation, distribution and reproduction in any medium or format, as long as you give appropriate credit to the original author(s) and the source, provide a link to the Creative Commons licence, and indicate if changes were made. The images or other third party material in this article are included in the article's Creative Commons licence, unless indicated otherwise in a credit line to the material. If material is not included in the article's Creative Commons licence and your intended use is not permitted by statutory regulation or exceeds the permitted use, you will need to obtain permission directly from the copyright holder. To view a copy of this licence, visit http:// creativecommons.org/licenses/by/4.0/.

Funding This work was supported by British Academy 180024.

\section{References}

Arnold, M. (1960). Emotion and personality. Cambridge: Cambridge University Press.

Byrne, A. (2001). Intentionalism Defended. Philosophical Review, 110(2), 199-240.

Cannon, W. (1927). The james-lange theory of emotions: A critical examination and an alternative theory. The American Journal of Psychology, 39, 106-124.

Claparède, E. (1928). Feelings and emotions. In M. L. Reymert (Ed.), Feelings and emotions: The wittenberg symposium (pp. 124-139). Worcester: Clark University Press.

Cobos, P. M., et al. (2002). Revisiting the James versus cannon debate on emotion: Startle and autonomic modulation in patients with spinal cord injuries. Biological Psychology, 61(3), 251-269.

Colombetti, G. (2011). Varieties of pre-reflective self-awareness: Foreground and background bodily feeling in emotion experience. Inquiry, 54(3), 293-313.

Crane, T. (2003). The intentional structure of consciousness. In A. Jokic \& Q. Smith (Eds.), Consciousness: New philosophical perspectives (pp. 1-27). Oxford: Oxford University Press. 
Crane, T. (2009). Intentionalism. In A. Beckermann \& B. P. McLaughlin (Eds.), The oxford handbook of the philosophy of mind (pp. 474-493). Oxford: Oxford University Press.

Damasio, A. (2006). Descartes error: Emotion, reason and the human brain. London: Random House.

De Sousa, R. (2002). Emotional truth. Oxford: Oxford University Press.

Dennett, D. (1978). Brainstorms. Cambridge: MIT Publishing.

Deonna, J. (2006). Emotion perception and perspective. Dialectica, 60(1), 29-46.

Deonna, J., \& Teroni, F. (2012). An introduction to the philosophy of the emotions. London: Routledge.

Deonna, J., \& Teroni, F. (2014). In what sense are emotions evaluations. In S. Roeser \& C. Todd (Eds.), Emotion and value (pp. 15-31). Oxford: Oxford University Press.

Deonna, J., \& Teroni, F. (2015). Emotions as attitudes. Dialectica, 69(3), 293-311.

Deonna, J., \& Teroni, F. (2017). Getting bodily feelings into emotional experience in the right way. Emotion Review, 9(1), 55-63.

Deonna, J., \& Teroni, F. (2020). Emotional experience: Affective consciousness and its role in emotion theory. In U. Kriegel (Ed.), Oxford handbook of the philosophy of consciousness. New York: Oxford University Press.

Dokic, J., \& Lemaire, S. (2015). Are emotions evaluative modes. Dialectica, 69(3), 271-292.

Dretske, F. (1999). Perception, knowledge and belief. Cambridge: Cambridge University Press.

Frijda, N. (1986). The emotions. Cambridge: Cambridge University Press.

Frijda, N. (2005). Emotion experience. Cognition and Emotion, 19(4), 473-497.

Frijda, N. (2007). The laws of emotion. London: Routledge.

Goldie, P. (2000). The emotions: A philosophical exploration. Oxford: Oxford University Press.

Harman, G. (1990). The intrinsic quality of experience. Philosophy of mind and action theory. Philosophical Perspectives, 4, 31-52.

Horgan, T., \& Tienson, J. (2002). The Intentionality of phenomenology and the phenomenology of intentionality. In D. Chalmers (Ed.), Philosophy of mind: Classical and contemporary readings (pp. 520-533). Oxford: Oxford University Press.

James, W. (1884). What is an emotion? Mind, 9, 188-205.

Johnston, M. (2001). The authority of affect. Philosophy and Phenomenological Research, 63(1), $181-214$.

Kriegel, U. (2013). The phenomenal intentionality research program. In U. Kriegel (Ed.), Phenomenal intentionality. Oxford: Oxford University Press.

Kriegel, U. (2014). Towards a new feeling theory of emotion. European Journal of Philosophy, 22(3), $420-442$.

Lambie, J. (2009). Emotion experience, rational action, and self-knowledge. Emotion Review, 1(3), $272-280$.

Lambie, J., \& Marcel, A. (2002). Consciousness and the variety of emotion experience: A theoretical framework. Psychological Review, 109(2), 219-259.

Lewin, K. (1938). The conceptual representation and the measurement of psychological forces. Contributions to psychol-ogical theory, 4. Durham: Duke University Press.

Lindquist, K., et al. (2012). The brain basis of emotion: A meta-analytic review. Behavioral and Brain Sciences, 35(2), 121-143.

Lyons, W. (1980). Emotion. Cambridge: Cambridge University Press.

Martin, M. (2002). The transparency of experience. Mind and Language, 4(4), 376-425.

Mitchell, J. (2020). The attitudinal opacity of emotional experience. Philosophical Quarterly, 70(280), 524-546.

Mitchell, J. (forthcoming). Emotions as feelings towards value. ms.

Müller, J. (2017). How (Not) to think of emotions as evaluative attitudes. Dialectica, 71(2), 281-308.

Nanay, B. (2011). Do we see apples as edible. Pacific Philosophical Quarterly, 92(3), 305-322.

Pitt, D. (2004). The phenomenology of cognition, or, what is it like to think that P. Philosophy and Phenomenological Research, 61(1), 1-36.

Poellner, P. (2016). Phenomenology and the perceptual model of emotion. Proceedings of the Aristotelian Society, 1(3), 1-28.

Prinz, J. (2004). Gut reactions: A perceptual theory of emotions. Oxford: Oxford University Press.

Rossi, M., \& Tappolet, C. (2018). What kind of evaluative states are emotions? The attitudinal theory vs the perceptual theory of emotions. Canadian Journal of Philosophy, 49(4), 544-563.

Sartre, J. P. (2004a). The transcendence of the ego: A sketch for a phenomenological description. London: Routledge.

Sartre, J. P. (2004b). Sketch for a theory of the emotions. London: Routledge. 
Scarantino, A. (2014). The motivational theory of emotions. In D. Jacobson \& J. D'Arms (Eds.), Moral psychology, and human agency (pp. 156-185). New York: Cambridge University Press.

Scheler, M. (1973, 1913-1916). Formalism in Ethics and Non-Formal Ethics of Values, trans. M. S. Frings \& R. L. Funk, Evanston, IL: Northwestern University Press.

Searle, J. (1983). Intentionality: An essay in the philosophy of mind. New York: Cambridge University Press.

Shoemaker, S. (1996). The first-person perspective and other essays. Cambridge: Cambridge University Press.

Siegel, S. (2010). The contents of visual experience. Oxford: Oxford University Press.

Slaby, J. (2008). Affective intentionality and the feeling body. Phenomenology and the Cognitive Sciences, 7(4), 429-444.

Smith, J. (2014). Are emotions embodied evaluative attitudes? Disputatio, 6(38), 93-106.

Stocker, M. (2010). Intellectual and other nonstandard emotions. In P. Goldie (Ed.), The oxford handbook of philosophy of emotion (pp. 401-423). Oxford: Oxford University Press.

Tappolet, C. (2016). Emotions, gency. Oxford: Oxford University Press.

Teroni, F. (2007). Emotions and formal objects. Dialectica, 61(3), 395-415.

Tye, M. (1995). Ten problems of consciousness. Cambridge: The MIT Press.

Tye, M. (2002). Representationalism and the transparency of experience. Nous, 36(1), 137-151.

Zahavi, D. (2005). Subjectivity and selfhood: Investigating the first-person perspective. London: MIT Press.

Publisher's Note Springer Nature remains neutral with regard to jurisdictional claims in published maps and institutional affiliations. 